\title{
Klasifikasi Data Aging Tunggakan Nasabah Menggunakan Metode Decision Tree Pada ULaMM Unit Kolaka
}

\author{
Sarimuddin', Jayanti Yusmah Sari $^{* 1}$, Muh. Mail², Muh. Ariyandhi Masalu², Reski Surya Aristika², \\ Nurfagra ${ }^{2}$ \\ ${ }^{1}$ Program Studi Ilmu Komputer, Universitas Sembilanbelas November Kolaka \\ ${ }^{2}$ Program Studi Sistem Informasi, Universitas Sembilanbelas November Kolaka \\ ${ }^{1}$ sarimuddin85@gmail.com, 1*jayanti@usn.ac.id
}

\begin{abstract}
This study aims to classify aging of loan data using the decision tree method based on plafond, outstanding principal, and the amount of loan. The subjects in this study were the debtor of ULaMM (Unit Layanan Modal Mikro), unit of Kolaka, PT. PNM (Persero) Kendari Branch. The number of samples used is 100 data debtors. Based on the results of the research conducted, it was found that the classification analysis using the Decision Tree has an accuracy rate of $95.00 \%$, while the classification analysis using the Gradient Boosted Tree has an accuracy level of $90.00 \%$. From the results of the analysis that has been done, it can be concluded that for the data in this study, the classification method using the Decision Tree is better than the Gradient Boosted Tree method.
\end{abstract}

Keyword: Decision Tree, Aging Tunggakan, Klasifikasi

\section{Pendahuluan}

Dalam bidang peminjaman modal, data aging tunggakan nasabah/debitur menjadi data yang paling penting yang dapat digunakan untuk memantau dan memastikan nasabah tidak melakukan penunggakan pembayaran angsuran. Secara etimologi, aging adalah kata benda dari lama tersimpan atau mengeram dan kata sifat dari sudah lanjut usia atau menjadi tua. Sedangkan secara terminologi, dalam bidang pembiayaan modal, aging berarti menentukan usia atau jangka waktu dari tunggakan nasabah [1]. Dengan demikian data aging tunggakan nasabah merupakan data yang memuat informasi tentang usia atau jangka waktu dari tunggakan nasabah.

ULaMM (Unit Layanan Modal Mikro) unit Kolaka adalah organisasi perusahaan yang menyalurkan pembiayaan modal bagi Usaha Mikro, Kecil, Menengah, dan Koperasi (UMKMK). ULaMM unit Kolaka berada di bawah naungan PT. PNM (Permodalan Nasional Madani) (Persero) cabang Kendari. PT. PNM (Persero) cabang Kendari memiliki MMS (Madani Management System) untuk melakukan pengawasan dan kendali terhadap aging tunggakan nasabah yang macet setiap bulan. Namun, kelemahan MMS (Madani Management System) terdapat pada data aging tunggakan nasabah yang bersifat global serta nominatif sehingga sulit untuk mengamati pergerakan DPD (Due Payment Date) angsuran nasabah [1]. Dengan demikian diperlukan analisis data aging tunggakan nasabah untuk untuk mengawasi nasabah (debitur) yang melakukan tunggakan pembayaran angsuran.

Analisis data aging tunggakan nasabah dapat dilakukan dengan menggunakan metode klasifikasi pada data mining. Klasifikasi merupakan suatu proses yang menemukan properti-properti yang sama pada sebuah himpunan objek di dalam sebuah basis data dan mengklasifikasikannya ke dalam kelas-kelas yang berbeda menurut model klasifikasi yang ditetapkan [2]. Dengan demikian, klasifikasi merupakan cara pengelompokkan data berdasarkan ciri-ciri yang dimiliki oleh data tersebut. Dalam data mining, beberapa metode yang sering digunakan untuk klasifikasi di antaranya Jaringan Syaraf Tiruan [3], Decission Tree dan Gradient Boosting Classifier [4]. Namun, metode yang paling sering digunakan adalah Decission Tree, karena metode ini memiliki beberapa kelebihan seperti dapat menghasilkan pohon keputusan yang mudah diinterprestasikan, memiliki tingkat akurasi yang dapat diterima, efisien dalam menangani atribut bertipe diskrit dan dapat menangani atribut bertipe diskrit dan numerik [5]. Selain itu, algoritma Decision Tree juga menghasilkan akurasi skor lebih tinggi dibandingkan algoritma klasifikasi lain seperti Gradient Boosting Classifier[4].

Penelitian ini akan melakukan klasifikasi data angsuran nasabah/debitur yang macet di ULaMM unit Kolaka, PT. PNM (Persero) Cabang Kendari berdasarkan data aging tunggakan nasabah menggunakan metode Decission Tree. Hasil klasifikasi selanjutnya akan digunakan untuk menganalisis angsuran nasabah 
yang macet dan jumlah nasabah sehingga diharapkan dapat membantu PT. PNM (Persero) Cabang Kendari untuk menentukan tingkat kesehatan pembiayaan modal pada ULaMM unit Kolaka. Sebagai perbandingan, akurasi hasil klasifikasi menggunakan metode Decision Tree akan dibandingkan dengan hasil klasifikasi menggunakan Gradient Boosting Classifier.

\section{Metodologi Penelitian}

Pada penelitian ini, klasifikasi data dilakukan sesuai dengan tahapan dalam data mining yaitu pengumpulan dataset, klasifikasi data menggunakan metode Decission Tree, dan analisis output pengetahuan (hasil klasifikasi) serta evaluasi akurasi dari hasil klasifikasi data [6].

\subsection{Klasifikasi Tunggakan}

Tunggakan bila ditinjau dari Kamus Besar Bahasa Indonesia memiliki arti angsuran yang belum dibayar. Menurut Peraturan Bank Indonesia No.14/15/PBI/2012 tentang kriteria kualitas kredit (tunggakan), tunggakan dikategorikan sebagai tunggakan lancar jika dalam durasi 0-1 hari, nasabah tidak memiliki tunggakan, dan dikategorikan sebagai tunggakan macet jika terdapat tunggakan dalam durasi $>180$ hari [7]. Metode yang digunakan oleh PT. PNM (Persero) Cabang Kendari, ULaMM Unit Kolaka dalam menentukan tunggakan macet atau tunggakan lancar merujuk ke Peraturan Bank Indonesia No.14/15/PBI/2012 tersebut. Sehingga, jika nasabah memiliki jumlah tunggakan dalam kurun waktu $>180$ hari, maka tunggakan nasabah tersebut diklasifikasikan sebagai tunggakan macet. Hal ini dapat dilihat pada contoh dataset (Gambar 1).

Adapun pada penelitian ini, untuk klasifikasi tunggakan nasabah dengan metode Decision Tree dan metode pembanding (Gradient Boosting Classifier), digunakan seluruh atribut pada dataset aging tunggakan nasabah (yaitu plafond, baki debet, jumlah tunggakan dan lama tunggakan). Hal ini berdasarkan hasil analisis terhadap metode yang digunakan oleh PT. PNM (Persero) Cabang Kendari, ULaMM Unit Kolaka yang belum dapat digunakan untuk mengamati pergerakan DPD (Due Payment Date) angsuran nasabah.

\subsection{Dataset}

Dalam penelitian ini, dilakukan pengumpulan data dengan mengambil objek penelitian yaitu data nasabah PT. PNM (Persero) Cabang Kendari, ULaMM Unit Kolaka. Data dalam penelitian ini diperoleh secara langsung dari kantor PT. PNM (Persero) Cabang Kendari, ULaMM Unit Kolaka. Dataset aging tunggakan nasabah akan diklasifikasi menjadi dua kategori yaitu tunggakan macet dan tunggakan lancar. Dan atribut yang terdapat dalam dataset aging tunggakan nasabah yaitu:

a. Plafond, batas tertinggi kredit yang disediakan.

b. Baki debet, saldo pokok dari plafond pinjaman yang telah disepakati dalam perjanjian kredit dan biasanya akan berkurang jika angsuran rutin dilakukan atau sesuai jadwal pembayaran oleh debitur.

c. Jumlah tunggakan.

d. Lama tunggakan, yakni 181-270 hari dan $\geq 271$ hari.

e. Keterangan, tunggakan lancar atau macet.

\begin{tabular}{|c|c|c|c|c|c|}
\hline Plafond & Baki debet & Jumlah Tunggakan & Tunggakan hari 181-270 & Tunggakan hari $>271$ & Keterangan \\
\hline $25,000,000$ & $11,126,533$ & $3,009,533$ & 0 & 0 & Lancar \\
\hline $20,000,000$ & $9,166,250$ & $1,482,231$ & 0 & 0 & Lancar \\
\hline $12,000,000$ & $8,579,400$ & $2,220,000$ & 0 & 0 & Lancar \\
\hline $25,000,000$ & $18,776,000$ & $1,540,251$ & 0 & 0 & Lancar \\
\hline $50,000,000$ & $3,033,239$ & $3,258,996$ & 0 & 3258996 & Macet \\
\hline $30,000,000$ & $1,025,700$ & $1,467,800$ & 0 & 1467800 & Macet \\
\hline $27,000,000$ & $14,759,350$ & $9,588,950$ & 1369850 & 0 & Macet \\
\hline $47,000,000$ & $5,382,050$ & $6,219,500$ & 0 & 0 & Lancar \\
\hline $50,000,000$ & $38,139,500$ & $9,555,600$ & 0 & 0 & Lancar \\
\hline $40,000,000$ & $21,768,350$ & $9,836,000$ & 0 & 0 & Lancar \\
\hline $50,000,000$ & $26,518,750$ & $18,922,550$ & 812450 & 0 & Macet \\
\hline $50,000,000$ & $43,103,050$ & $20,960,100$ & 6986700 & 0 & Macet \\
\hline $50,000,000$ & $36,699,300$ & $6,986,700$ & 0 & 0 & Lancar \\
\hline $30,000,000$ & $12,602,900$ & $1,811,000$ & 0 & 0 & Lancar \\
\hline $40,000,000$ & $31,391,550$ & $5,733,300$ & 0 & 0 & Lancar \\
\hline $40,000,000$ & $22,089,250$ & $4,829,300$ & 0 & 0 & Lancar \\
\hline $35,000,000$ & $28,213,050$ & $3,344,400$ & 0 & 0 & Lancar \\
\hline $35,000,000$ & $28,213,050$ & $3,344,400$ & 0 & 0 & Lancar \\
\hline $50,000,000$ & $42,115,850$ & $9,285,172$ & 0 & 0 & Lancar \\
\hline $30,000,000$ & $19,172,150$ & $1,850,000$ & 0 & 0 & Lancar \\
\hline $50,000,000$ & $40,048,300$ & $2,265,999$ & 0 & 0 & Lancar \\
\hline $37,000,000$ & $26,446,750$ & $7,017,000$ & 0 & 0 & Lancar \\
\hline $30,000,000$ & $24,658,650$ & $1,397,350$ & 0 & 0 & Lancar \\
\hline $30,000,000$ & $22,531,050$ & $5,550,000$ & 5385300 & 1795100 & Macet \\
\hline $34,500,000$ & $34,500,000$ & $17,951,000$ & 0 & 0 & Lancar \\
\hline $35,000,000$ & $29,481,400$ & $1,630,200$ & 5271939 & 0 & Macet \\
\hline
\end{tabular}


Adapun 150 sampel data aging tunggakan nasabah yang digunakan untuk mengklasifikasi nasabah yang yang lancar dan macet yaitu 100 sampel sebagai data uji dan 50 sampel sebagai data latih, diperoleh dari kantor PT. PNM (Persero) Cabang Kendari, Unit Kolaka. Gambar 1 adalah contoh data aging tunggakan nasabah yang akan digunakan dalam klasifikasi aging tunggakan nasabah yang lancar atau macet.

Berdasarkan data aging tunggakan nasabah, kemudian dilakukan pemilihan atribut dan sebagian dari data dalam atribut yang ada akan ditransformasikan untuk memudahkan proses mining dalam menentukan atribut keterangan (angsuran macet atau lancar). Adapun data aging tunggakan yang digunakan untuk menentukan angsuran macet atau lancar yaitu 50 sampel data aging tunggakan yang diambil secara acak dari data 150 data yang diperoleh. Dengan demikian diperoleh data hasil transformasi dengan tiga atribut (plafond, baki debet dan jumlah tunggakan) yang akan dijadikan atribut predictor atau atribut input, dan atribut target (keterangan), di mana atribut target tersebut menjadi class output untuk mengklasifikasi aging tunggakan nasabah yang dibedakan menjadi 2 kelas yaitu lancar dan macet. Gambar 2 berikut adalah contoh data aging tunggakan nasabah yang akan digunakan dalam klasifikasi aging tunggakan nasabah yang lancar atau macet.

\begin{tabular}{|c|c|c|c|}
\hline Plafond & Baki debet & Jumlah Tunggakan & Keterangan \\
\hline $25,000,000$ & $11,126,533$ & $3,009,533$ & Lancar \\
\hline $20,000,000$ & $9,166,250$ & $1,482,231$ & Lancar \\
\hline $12,000,000$ & $8,579,400$ & $2,220,000$ & Lancar \\
\hline $25,000,000$ & $18,776,000$ & $1,540,251$ & Lancar \\
\hline $50,000,000$ & $3,033,239$ & $3,258,996$ & Macet \\
\hline $30,000,000$ & $1,025,700$ & $1,467,800$ & Macet \\
\hline $27,000,000$ & $14,759,350$ & $9,588,950$ & Macet \\
\hline $47,000,000$ & $5,382,050$ & $6,219,500$ & Lancar \\
\hline $50,000,000$ & $38,139,500$ & $9,555,600$ & Lancar \\
\hline $40,000,000$ & $21,768,350$ & $9,836,000$ & Lancar \\
\hline $50,000,000$ & $26,518,750$ & $18,922,550$ & Macet \\
\hline $50,000,000$ & $43,103,050$ & $20,960,100$ & Macet \\
\hline $50,000,000$ & $36,699,300$ & $6,986,700$ & Lancar \\
\hline $30,000,000$ & $12,602,900$ & $1,811,000$ & Lancar \\
\hline $40,000,000$ & $31,391,550$ & $5,733,300$ & Lancar \\
\hline $40,000,000$ & $22,089,250$ & $4,829,300$ & Lancar \\
\hline $35,000,000$ & $28,213,050$ & $3,344,400$ & Lancar \\
\hline $35,000,000$ & $28,213,050$ & $3,344,400$ & Lancar \\
\hline $50,000,000$ & $42,115,850$ & $9,285,172$ & Lancar \\
\hline $30,000,000$ & $19,172,150$ & $1,850,000$ & Lancar \\
\hline $50,000,000$ & $40,048,300$ & $2,265,999$ & Lancar \\
\hline $37,000,000$ & $26,446,750$ & $7,017,000$ & Lancar \\
\hline $30,000,000$ & $24,658,650$ & $1,397,350$ & Lancar \\
\hline $30,000,000$ & $22,531,050$ & $5,550,000$ & Macet \\
\hline $34,500,000$ & $34,500,000$ & $17,951,000$ & Lancar \\
\hline $35,000,000$ & $29,481,400$ & $1,630,200$ & Macet \\
\hline
\end{tabular}

Gambar 2. Contoh data hasil transformasi

\subsection{Decision Tree}

Decision tree adalah salah satu metode klasifikasi yang paling popular karena mudah diinterpretasikan oleh manusia [8]. Decision tree digunakan untuk pengenalan pola dan termasuk dalam pengenalan pola secara statistik. Decision tree dibentuk dari 3 tipe dari simpul, yaitu simpul leaf yang memuat suatu akhir atau kelas target untuk suatu pohon keputusan, simpul root yang merupakan titik awal dari suatu decision tree, dan simpul perantara yang berhubungan dengan suatu pertanyaan atau pengujian [9].

Proses dalam decision tree adalah mengubah bentuk data (tabel) menjadi model tree, mengubah model tree menjadi rule, dan menyederhanakan rule (pruning). Untuk menentukan atribut terbaik, digunakan properti statistik yang disebut information gain, yang mengukur seberapa handal sebuah atribut dalam memisahkan sampel latihan menurut klasifikasi targetnya. Untuk menentukan information gain secara tepat, dimulai dengan menentukan sebuah ukuran, dalam teori informasi disebut entropi, yang mengkarakterisasikan kemurnian/ketakmurnian dari sebuah koleksi acak dari sampel. Dengan sebuah koleksi $S$, yang berisi sampel positif dan negatif dari target, entropi dari $S$ relatif terhadap klasifikasi Boolean adalah [9]:

$$
\operatorname{Entropi}(S)=-P_{+} \log _{2} P_{+}-P_{-} \log _{2} P_{-}
$$

Keterangan:

$P_{+}$adalah proporsi sampel positif dalam $\mathrm{S}$.

$P_{-}$adalah proporsi sampel negatif dalam $\mathrm{S}$.

Dalam semua perhitungan mengikutkan entropi ditentukan bahwa $0 * \log _{2} 0$ adalah 0 . 
Jika atribut target bisa memiliki $c$ kemungkinan nilai yang berbeda, maka entropi dari $S$ terhadap klasifikasi $c$ ditentukan menggunakan Persamaan (2) berikut [10]:

$$
\operatorname{Entropi}(S)=\sum_{i=1}^{c}-p_{i} \log _{2} p_{i}
$$

dengan $p_{i}$ adalah proporsi kelas $I$ terhadap $S$. Dari nilai entropi kemudian dapat dihitung information gain, Gain (S,A) dari atribut relatif $A$ terhadap kumpulan sampel $S$, menggunakan Persamaan (3) [10]:

$$
\operatorname{Gain}(S, A)=\operatorname{Entropi}(S)-\sum_{i=1}^{c}-\frac{\left|s_{i}\right|}{|s|} * \operatorname{Entropi}\left(s_{i}\right)
$$

dengan jumlah partisi atribut A sebanyak $c$, jumlah kasus pada partisi ke- $i$ sebanyak $\left|s_{i}\right|$ dan jumlah kasus dalam $S$ sebanyak $|s|$.

\subsection{Pengukuran Performance}

Untuk mengukur performance dari hasil klasifikasi menggunakan Decision Tree pada penelitian ini, digunakan acuan confusion matrix yang meliputi akurasi, recall, precission dan specificity. Akurasi (Persamaan 4) merupakan rasio prediksi benar (positif dan negatif) dengan keseluruhan data. Adapun, precission (Persamaan 5) merupakan rasio prediksi benar positif dibandingkan dengan keseluruhan hasil yang diprediksi positf. Recall (Persamaan 6) merupakan rasio prediksi benar positif dibandingkan dengan keseluruhan data yang benar positif. Dan specificity merupakan kebenaran memprediksi negatif dibandingkan dengan keseluruhan data negatif [11]. Dengan demikian pada penelitian ini akan digunakan ukuran akurasi, recall dan precission, sedangkan specificity tidak digunakan dalam penelitian ini karena tidak sesuai dengan

\begin{tabular}{|c|c|c|c|}
\hline & \multicolumn{2}{|c|}{ Tabel 1. Confusion Matrix } \\
\hline & & \multicolumn{2}{|c|}{ Nilai sebenarnya } \\
\hline & & Positif (1) & Negatif $(0)$ \\
\hline \multirow{2}{*}{ 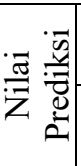 } & Positif (1) & $\begin{array}{c}\text { True } \\
\text { Positive (TP) }\end{array}$ & $\begin{array}{c}\text { False } \\
\text { Positive (FP) }\end{array}$ \\
\hline & Negatif (0) & $\begin{array}{c}\text { False } \\
\text { Negative (FN) }\end{array}$ & $\begin{array}{c}\text { True } \\
\text { Negative (TN) }\end{array}$ \\
\hline
\end{tabular}
tujuan penelitian. Tabel 1 berikut menunjukkan confusin matrix [11]

$$
\begin{aligned}
& \text { Akurasi }=(\mathrm{TP}+\mathrm{TN}) /(\mathrm{TP}+\mathrm{FP}+\mathrm{FN}+\mathrm{TN}) \\
& \text { Precission }=(\mathrm{TP}) /(\mathrm{TP}+\mathrm{FP}) \\
& \text { Recall }=(\mathrm{TP}) /(\mathrm{TP}+\mathrm{FN})
\end{aligned}
$$

\section{Analisis Hasil dan Pembahasan}

Semua atribut indikator input dan atribut tujuan dalam dataset, kemudian diolah ke menggunakan software Data Mining yaitu RapidMiner Studio 9.4.001. Gambar 3 berikut menunjukkan desain proses data mining untuk klasifikasi data aging tunggakan nasabah menggunakan metode decision tree pada aplikasi RapidMiner Studio.

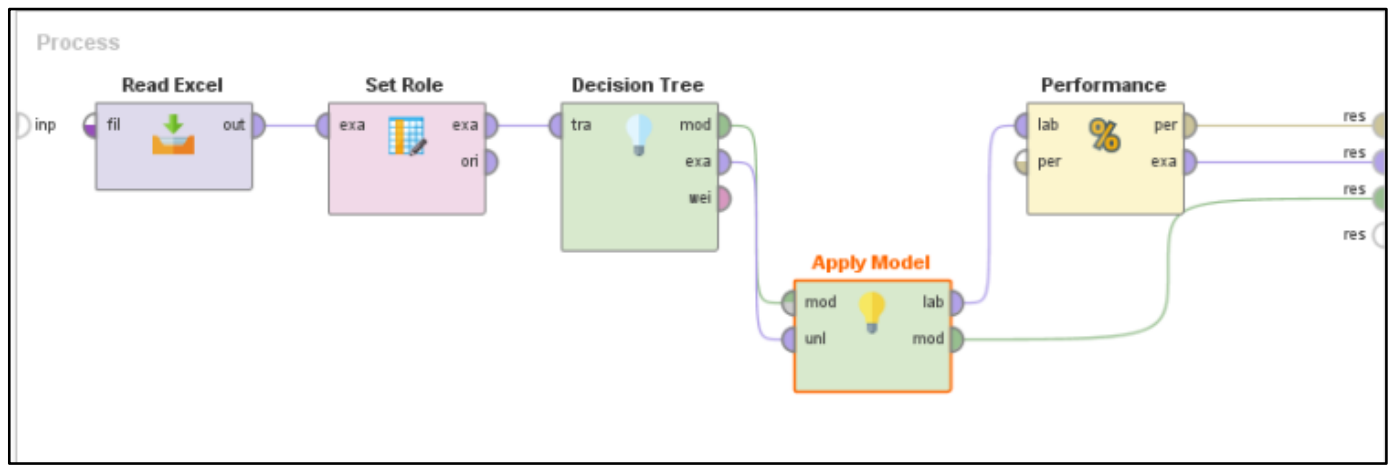

Gambar 3. Desain proses data mining 
Hasil dari proses data mining yang ditunjukkan pada Gambar 3 adalah sebuah decision tree atau pohon keputusan untuk proses klasifikasi data aging tunggakan nasabah seperti yang dapat dilihat pada Gambar 4. Dari decision tree tersebut dapat dilihat bahwa atribut yang menjadi root adalah jumlah tunggakan, lalu diikuti oleh atribut baki debet dan plafond sebagai simpul perantara. Gambar 4 menunjukkan bahwa dengan metode decision tree, seorang nasabah diklasifikasikan sebagai nasabah dengan aging tunggakan macet jika:

a. jumlah tunggakannya $>18.436 .775$, atau

b. jumlah tunggakan $\leq 18.436 .775$ dan baki debetnya $\leq 4.207 .644,500$, atau

c. jumlah tunggakan $>18.436 .775$ dan plafond-nya $>44.750 .000$, atau

d. jumlah tunggakan $\leq 1.720 .600$ dan plafond-nya $>32.500 .000$

Sedangkan nasabah yang diklasifikasikan sebagai nasabah dengan aging tunggakan lancar jika 18.436.775 $\geq$ jumlah tunggakan $>1.720 .600$, baki debetnya $>4.207 .644,500$ dan plafond-nya $\leq 44.750 .000$.

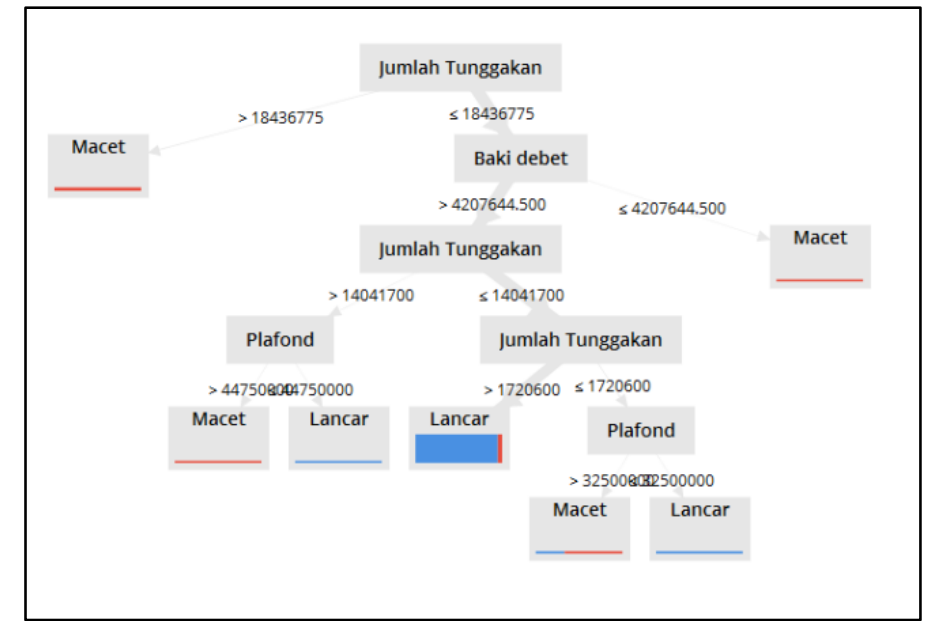

Gambar 4. Decision tree klasifikasi data aging tunggakan nasabah

Dengan menggunakan decision tree atau pohon keputusan pada Gambar 3, berikut hasil klasifikasi data aging tunggakan nasabah yang diperoleh:

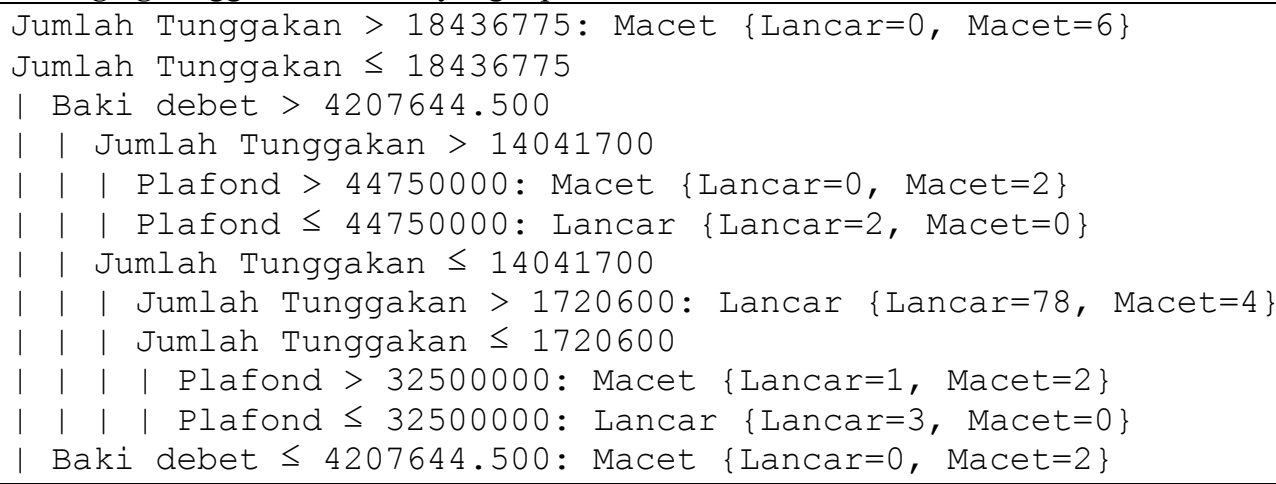

Selanjutnya, dilakukan evaluasi dan analisis hasil klasifikasi tersebut menggunakan confusion matrix sehingga diperoleh nilai recall untuk hasil klasifikasi angsuran lancar sebesar 98,81\% dan angsuran macet sebesar $75,00 \%$. Hal ini menunjukkan jika metode decision tree cukup baik untuk mengklasifikasi angsuran macet sebesar $75 \%$ dari jumlah angsuran macet yang ada. Adapun untuk nilai precission diperoleh 95,40\% untuk angsuran lancar dan 92,31\% untuk angsuran macet. Hal ini menunjukkan bahwa pada semua hasil klasifikasi angsuran yang macet menggunakan metode decision tree terdapat 92,31\% angsuran yang benar macet. Adapun hasil evaluasi ini dapat dilihat pada Tabel 2.

Tabel 2. Hasil klasifikasi menggunakan Decision Tree

\begin{tabular}{cccc}
\hline & Lancar (true) & Macet (true) & Class precission \\
\hline Klasifikasi (lancar) & 83 & 4 & $95,40 \%$ \\
\hline Klasifikasi (macet) & 1 & 12 & $92,31 \%$ \\
\hline Class recall & $98,81 \%$ & $75,00 \%$ & \\
\hline
\end{tabular}


Sebagai perbandingan, pada penelitian ini juga dilakukan klasifikasi menggunakan metode Gradient Boosting Classifier. Dan hasilnya akan dibandingkan dengan hasil klasifikasi sebelumnya yang menggunakan Decision Tree. Perbandingan hasil klasifikasi kedua metode tersebut ditunjukkan pada Gambar 5. Dari Gambar 5 tersebut, dapat dilihat bahwa hasil klasfikasi menggunakan metode Decision Tree memiliki nilai akurasi sebesar 95\%, recall angsuran lancar 98,81\%, recall angsuran macet 75,00\%, precission angsuran lancar 95,40\% dan precission angsuran macet 92,31\%. Sedangkan metode Gradient Boosting Classifier memiliki nilai akurasi sebesar 90\%, recall angsuran lancar 89,29\%, recall angsuran macet 93,75\%, precission angsuran lancar $98,68 \%$ dan precission angsuran macet $62,50 \%$. Dengan demikian, secara umum dapat disimpulkan bahwa hasil klasifikasi menggunakan metode Decision Tree lebih baik dibandingkan dengan metode Gradient Boosting Classifier.

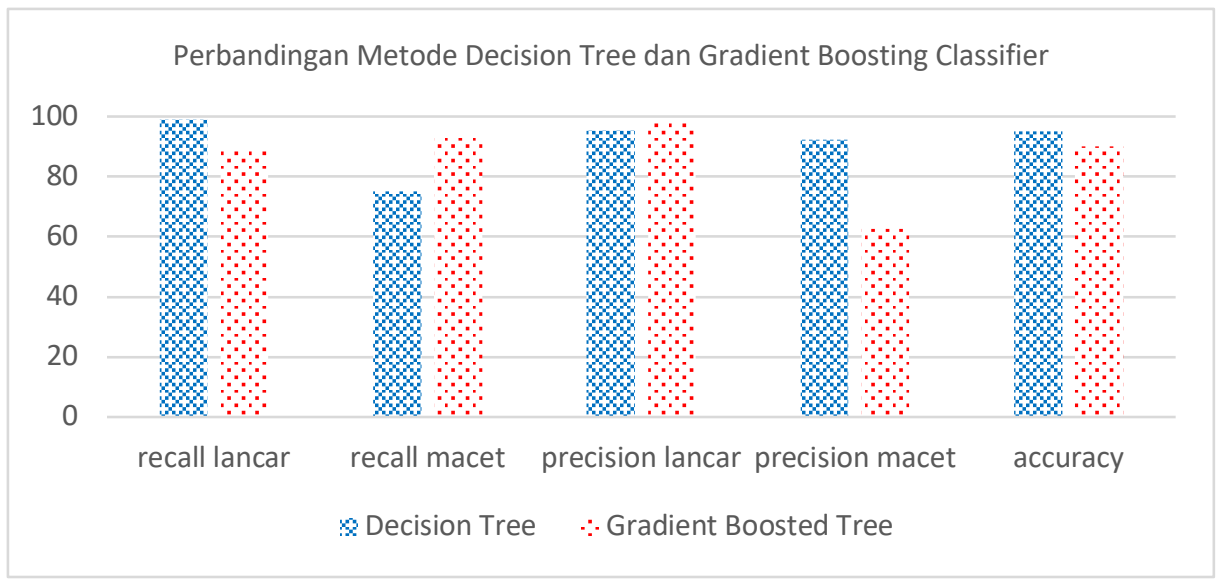

Gambar 5. Perbandingan hasil klasifikasi menggunakan Decision tree dan Gradient Boosting Classifier

\section{Kesimpulan}

Pada penelitian ini, dilakukan klasifikasi data aging tunggakan nasabah di ULaMM unit Kolaka, PT. PNM (Persero) Cabang Kendari untuk menentukan nasabah dengan angsuran yang macet dan tidak macet (lancar). Hasil klasifikasi menunjukkan tingkat akurasi sebesar 95\%. Sebagai perbandingan, akurasi ini dibandingkan dengan hasil klasifikasi menggunakan metode Gradient Boosting Classifier, dan diperoleh tingkat akurasi sebesar 90\%. Dengan demikian dapat disimpulkan bahwa untuk data pada penelitian ini metode Decision Tree lebih baik dibandingkan dengan metode Gradient Boosting Classifier.

\section{References}

[1] A. H. Siregar, "Sistem Informasi Aging Tunggakan Pembiayaan Modal Mikro Dalam Pemberian Kredit Di PT. Permodalan Nasional Madani (Persero) Cabang Bandung," Doctoral Dissertation, Universitas Komputer Indonesia, 2013.

[2] S. L. B. Ginting, W. Zarman, and I. Hamidah, "Analisis dan Penerapan Algoritma C. 45 Dalam Data Mining Untuk Memprediksi Masa Studi Mahasiswa Berdasarkan Data Nilai Akademik," in Seminar Nasional Aplikasi Sains dan Teknologi (SNAST), Yogyakarta, 2014.

[3] A. R. M. H. N. Asegaff, "Prediksi Kemacetan Angsuran Leasing Motor Menggunakan Algoritma Backprpagation Neural Network Berbasis Particle Swarm Optom,” Technol. J. Ilm., vol. 8, no. 4, p. 243, 2017.

[4] K. B. Adhinata, "Implementasi Algoritma Decision Tree Classifier Untuk Klasifikasi Pelanggan Provider X Pada E-Commerce Sepulsa,” Doctoral Dissertation, Universitas Ciputra, 2019.

[5] M. Ridwan, H. Suyono, and M. Sarosa, "Penerapan Algoritma Decision Tree ID3 Untuk Prediksi Kelulusan Mahasiswa Jenjang Pendidikan D3 Di Fakultas Teknik," J. EECCIS, vol. 5, no. 2, pp. 1-6, 2019.

[6] A. Sucipto, "Pada Koperasi Simpan Pinjam Dengan Menggunakan,” J. DISPROTEK, vol. 6, no. 1, pp. 75-87, 2015.

[7] A. Himawan, G. S. Wijaya, W. Mahmud, and Z. Arifin, "Faktor-Faktor Yang Mempengaruhi Tingkat Kolektibilitas Debitur di PT . Bank China Construction Bank Indonesia," vol. 01, no. 2, 2018.

[8] Y. Elmande and P. Widodo, "Pemilihan Criteria Splitting dalam Algoritma Iterative Dichotomiser 3 (ID3) untuk Penentuan Kualitas Beras: Studi Kasus Pada Perum Bulog Divre Lampung,” J. Telemat. MKOM, vol. 4, no. 1, p. 10, 2012.

[9] A. P. Wibawa, M. Guntur, A. Purnama, M. F. Akbar, and F. A. Dwiyanto, "Metode-metode Klasifikasi," Pros. Semin. Ilmu Komput. dan Teknol. Inf., vol. 3, no. 1, pp. 134-138, 2018.

[10] M. Firmansyah and R. Aufany, "Implementasi Metode Decision Tree Dan Algoritma C4.5 Untuk Klasifikasi 
Data Nasabah Bank," Infokam, vol. XII, no. 1, pp. 1-12, 2016.

[11] B. Juba and H. S. Le, "Precision-Recall versus Accuracy and the Role of Large Data Sets," Proc. AAAI Conf. Artif. Intell., vol. 33, pp. 4039-4048, 2019. 